\title{
An Efficeint Operations Management Strategy using Fuzzy Logic Decision Making based shop floor control technique
}

\author{
K.Kavitha, R.Muruganandham, J.Dinesh, A.Mohammed Raheel Basha
}

\begin{abstract}
In any organization, shop floor control seems to be a vital and pivotal activity and effective shop floor control paves the way for cent percet production. Effective utilization of resources, proper production planning and successful maintainence would always pave the way for high productivity which in turn fulfils the commitment to meet out the delivery schedule for custoemers. Hence it is understood that continous and consistent shop floor management demands a serious focus that contributes for sound operations management. More developments have taken place in the recent decade in framing new methodologies and adopting new advanced techniques to control the shop floor acivities of an organization. The purposes of our paper is to bring out a new model for shop floor control using Fuzzy Logic Decision Taking technique to help the operations professionals to enable them for successful professional decision making in shop floor control. Multi Criteria Decision Making (MCDM) Techniques have witnessed tremendous application in operations management. Our paper has successfully attempted to apply Fuzzy Logic Decision Making Technique which is one among the various MCDM tools. The technique considers many factors like Production, Wastages, Breakdown or Idle Time etc and these factors are treated as criteria and upon using the tool, the Management Information System(MIS) resports generated after mathermatical manipulation using Fuzzy Logic seems to be much usedful for corporate decision making.
\end{abstract}

Index Terms: MCDM, Fuzzy Logic, Decision, Manufcturing , Inventory.

\section{INTRODUCTION}

It was in early 1970s Multictiteria Decision Making Technique Models got evolved and gradually found their application in various decision making situations [1]. However, Fuzzy Logic initially found its wide application only for engineering design [2]. Multi criteria Decision Making (MCDM) technqiues that got evolved from Optimization Princples are scientific in approach and the techniques were commonly used in many manufacturing cum maintenance associated areas[3]. MCDM is a sub discipline of operations research that explicitly considers multiple criteria in decision making environments. In our daily life occassionally we come across multiple conflicting criteria that need to be evluated while making decisions. Even while

Revised Manuscript Received on July 05, 2019

K.Kavitha, School of Management, SRM Institute of Science and Technology, Kattankulattur, Chennai, Tamizhnadu, India.

Dr.R.Muruganandham, School of Management, SRM Institute of Science and Technology, Kattankulattur, Chennai, Tamizhnadu, India.

J.Dinesh, School of Management, SRM Institute of Science and Technology, Kattankulattur, Chennai, Tamizhnadu, India.

A.Mohammed Raheel Basha, School of Management, SRM Institute of Science and Technology, Kattankulattur, Chennai, Tamizhnadu, India. purcasing a car cost, comfort etc, need to be considered in selecting an appropriate car[4] The fusion of MCDM and Fuzzy Set Theroy has wide acceptance among decision scientists [5]. The paper is structured initially with literature review, modelling and illustration, results and findings followed by conclusion and bibiligraphy.

\section{LITERATURE}

Shop Floor Control techniques have always been given prirotiy in any organization to track, follow up and report about updates in productivity and in fact any effective operational strategy would always stand as a back bone for corporate decision making[6]. Fuzzy decision approach has occupied a significant role in integrating manufacturing and disstribution planning decisins in shop floor control[7] and Fuzzy appraoch has been successsfully applied for supplier evaluation [8], evaluation of competencies[9] and tender selection in public office[10]. Many papers that were published using Fuzyy Approach in manufacturing integrating supply chain and production reveal the methodologies that how fuzzy decision modelling was evolved for supply chain management [11] and Inventory Management[12]. Meanwhile many text books have highlighted the need of any customized software model to monitor and audit production [13].

\section{MODELLING AND ILLUSTRATION}

The modelling suggested for the purchase of car[4] is followed for shop floor control here and for the simple illustration, three criteria named Machine Idle Time(Weekly in Minutes),Wasteages(g) and Production(Kg) have been assumed and considered and the asuumed data given as below in Table[1].

\begin{tabular}{|c|c|c|c|}
\hline Machines & $\begin{array}{c}\text { Idle } \\
\text { Time }\end{array}$ & Wastages & Production \\
\hline M1 & 84 & 42 & 90 \\
\hline M2 & 70 & 42 & 92 \\
\hline M3 & 60 & 40 & 85 \\
\hline M4 & 42 & 38 & 90 \\
\hline M5 & 42 & 40 & 90 \\
\hline M6 & 15 & 90 & 85 \\
\hline M7 & 12 & 60 & 75 \\
\hline M8 & 25 & 50 & 82 \\
\hline
\end{tabular}

Published By:

Blue Eyes Intelligence Engineering

\& Sciences Publication 
The membership values are tabulated inTable [2].

\begin{tabular}{|c|c|c|c|}
\hline Machines & $\boldsymbol{\mu}_{\mathbf{i}}$ & $\boldsymbol{\mu}_{\mathbf{w}}$ & $\boldsymbol{\mu}_{\mathbf{p}}$ \\
\hline M1 & 0.3 & 0.8 & 0.9 \\
\hline M2 & 0.4 & 0.8 & 0.92 \\
\hline M3 & 0.5 & 0.8 & 0.85 \\
\hline M4 & 0.7 & 0.78 & 0.9 \\
\hline M5 & 0.7 & 0.8 & 0.9 \\
\hline M6 & 0.95 & 0.3 & 0.85 \\
\hline M7 & 0.98 & 0.6 & 0.75 \\
\hline M8 & 0.85 & 0.7 & 0.82 \\
\hline
\end{tabular}

The average membership values are $\mathrm{AVi}=0.6725$, $\mathrm{AVw}=0.6975$ and $\mathrm{AVp}=0.8612$.

The Representative Factors areRi $=0.3725, \mathrm{Rw}=0.3975$ and $\mathrm{Rp}=0.0 .5612$.

The Flexibility values are $\mathrm{e}_{\mathrm{i}}=0.6275, \mathrm{e}_{\mathrm{w}}=0.6025$ and $\mathrm{e}_{\mathrm{p}}=0.4388$.

Cosnidering $e_{i}$ with respect to all the Machines from Set 1, $\{\mathrm{M} 1 . \mathrm{M} 2 \mathrm{M} 3, \mathrm{M} 4, \mathrm{M} 5, \mathrm{M} 6, \mathrm{M} 7, \mathrm{M} 8\}$, the shortlisted machines are $\{\mathrm{M} 7, \mathrm{M} 6, \mathrm{M} 8, \mathrm{M} 5, \mathrm{M} 4\}-$ Set 2

Considering $\mathrm{e}_{\mathrm{w}}$ for Set 2, the shortlisted machines are \{M4,M5,M8\}--Set3

Considering $e_{p}$ for Set3, the machines from Set 3 aer ranked as $\{\mathrm{M} 5, \mathrm{M} 4, \mathrm{M} 8\}$

The above illustration could also be coded in any programming language like $\mathrm{C}$.

\section{C PROGRAM FOR NUMERICAL EXAMPLE}

\# include <stdio.h>

$\operatorname{Int} \boldsymbol{\mu}_{\mathrm{p}}, \mathbf{e}_{\mathrm{p}}, \boldsymbol{\mu}_{\mathrm{w}}, \mathbf{e}_{\mathrm{w}}, \boldsymbol{\mu}_{\mathrm{i}}, \mathbf{e}_{\mathrm{i}}$

Main()

\{

Printf("Give the value of $\boldsymbol{\mu}_{\mathbf{p}}$ ");

$\operatorname{scanf}\left(" \% \mathrm{~d} ", \quad \& \mu_{\mathrm{p}}\right)$;

Printf("Give the value of $\mathbf{e}_{\mathbf{p}}$ ");

Scanf(“\%d", \& $\mathbf{e}_{\mathbf{p}}$ );

Printf("Give the value of $\boldsymbol{\mu}_{\mathbf{w}}$ ");

Scanf(“\%d", \& $\left.\mu_{\mathrm{w}}\right)$;

Printf("Give the value of $\mathbf{e}_{\mathbf{w}}$ ");

Scanf(“5d", \& $\mathbf{e}_{\mathbf{w}}$ );

Printf("Give the value of $\boldsymbol{\mu}_{\mathbf{i}}$ ");

Scanf(“\%d", \& $\boldsymbol{\mu}_{\mathrm{i}}$ );

Printf("Give the value of $\mathbf{e}_{\mathbf{i}}$ ");

Scanf(“\%d”, \& $\left.\mathbf{e}_{\mathrm{i}}\right)$;

If $\left(\boldsymbol{\mu}_{\mathbf{p}}>\mathbf{e}_{\mathbf{p}}\right)\{$

Printf("set 1 to be processed");

\}

else

If $\left(\boldsymbol{\mu}_{\mathbf{w}}>\mathbf{e}_{\mathrm{w}}\right)\{$

Printf("set 2 to be processed");

\}

else

if $\left(\boldsymbol{\mu}_{\mathbf{i}}>\mathbf{e}_{\mathbf{i}}\right)($

printf("set 3 to be processed");

\}

In the above program the symbol " $\mu$ " was included for user understanding and this is not acceptable for $\mathrm{C}$ language.

\section{V.RESULT AND FINDINGS}

1. In a general outlook, if we want to choose any machine based on any of the criteria it would be easy to select M7 on the basis of lowest idle time. But the conflict here is M7 hos more wastages and low production. Similarly on the basis of Wastages M4 might be chisen, but it has more idle time eventhough the productin is higher. The numerical illustration clearly shows that machine M8 seems to be modertely highly peforming machine whereas machines M5 and M4 are moderately performing as their idle time is more than that of M8. But based on production the best machine is M2 but the idle is more. It is only to resolve this conflicting selection, Fuzzy Logic Decsion Making has been adopted .

2. This model once installed would help us for good decision making.

3. Suppose if there are 50 Machines in a shop floor,the model could be tried for 10 times by gradually eleminating best performing machine one by one and major care could be exercized for other machines by planning routing preventive maintenance

4. The model can be applied for miscellaneous applications where selection is confusing and conflicting with many criteria.

5. Management Information System(MIS) Reports could be evolved and customized for the specific requirement.

\section{CONCLUSION}

The model presented here could be considered for any number of machines with database, software and hardware infrsstrcture. The Operating System might be chosen with more secutiry aspects and restricted registered users. In all developing management support systems, Fuzzy Logic[16] is gaining more popularity in the new develpping era of decision sciences.More developments are taking in MCDM field and the same Fuzzy Logic Decision Making could be extendted to apply with criteria and constraints too[17]. Multi Objective Decision Making Models using Fuzzy Logic[18] have been evolving in every nook and corner of the globe in operations management . Most of the advanced expert systems for manufacturing[19] interestingly make use of Fuzzy Logic. MCDM tecnique with Fuzzy Logic could also be used for ranking[20] Shop Floor dispatching rules and enable decision making in classical multi production inventory system[21]

\section{REFERENCES}

[1] C. Carlson and R.Fuller, Fuzzy Multiple Criteria Decision making: Recent Developments, Fuzzy Sets and Systems, 78, 139-153 (1996).

[2] Timothy.J.Ross, Fizzy Logic with Engineering Applications, Wiley India (1995).

[3] Dawood Dabei, A review of multi criteria decision making methods for enhanced maintenance dewlivery, Elsevier, Procedia CIRP, 37, 30-35 (2015).

[4] B.K.Mohanty, Product classification in the Internet Business- a fuzzy approach, Elsevier, Decision Support Systems, 38 (2005)

[5] Lazim Abdullah," Fuzzy Muti Criteria Deciaion Making and its Application-a brief review of category", Elsevier, Procedia Social and Behavioural Sciecnes, 97, 131-136 (2013).

[6] K.Ravichandran, T.Sornakumar,"An operational strategy for effetive spare parts management: A case study with valudation by Fuzzy Logic", Inernational Journal for Business and Management and Studies, 2(2) (April-June 2012).

[7] Tien-Fu Liang, Application of Fuzzy Sets to manufacturing 
/distribution planning decisions in supply chains, Elsevier,Information Sciences 181, 842-854, 2011.

[8] C. T. Chen, C. T. Lin, S. F. Huang, A fuzzy approach for supplier evaluation and selection in supply chain management, International Journal of Production Economics, 102(2), 289-301 (2006).

[9] Pépiot, N. Cheikhrouhou, J. M. Fürbringer, R. Glardon, "A fuzzy approach for the evaluation of competences", International Journal of Production Economics, 112(1), 336-353 (2008).

[10] T. Y. Hsieh, S. T. Lu, G. H. Tzeng,"Fuzzy MCDM approach for planning and design tenders selection in public office buildings", International Journal of Project Management, 22(7), 573-584, 2004.

[11] Juite Wang, Yun-Feng Shu, Fuzzy decision modelling for supply chainmanagement, Elsevier, Fuzzy Sets and Systems, 150, 107-127 (2005).

[12] Lushu Li,S.N.Kabadi,elsevier,"Fuzzy Models for single period inventory problem",Elsevier, Fuzzy Sets and Systems, 132, 273-289 (2002).

[13] S.Kant Vakpayee, Principles of Computer-Integrated Manufacturing, Prentice- Hall of India Pvt Ltd., New Delhi (2003).

[14] Dr. K. Sundareswaran, A Learner's Guide to Fuzzy Logic, Jaico Books, Delhi (2008).

[15] Timothy J. Ross, Fuzzy Logic with Engineering Applications, Wiley India, Delhi (2010).

[16] Rafik Aliev, Fuzzy Logic based generalized decision theory with imperfect information, Elsevier, Information Sciences, 189, 18-42, 2012.

[17] N.Chakraborty,"A deteriorating multi-item inventory modelwith price discount and variable demands via fuzzy logic under resource constraints",Elsevier,Computers and Indsutrial Engineering, 66, 976-987 (2013).

[18] Jiuping Xu, Multi Objective Decision Making Model under fuzzy random environment and its application to inventory probkems, Elsevier,Information Sciences, 178 (2008)

[19] Fei-Long Chen, Yun-Chin Chen, Applying Moving back propagation neural network and Moving fuzzy -neuron network to predict the requiremtn of critical spare parts, Elsevier, Expert Systems with Applications, 37, 6695-6704 (2010).

[20] Alberto Petroni, Fuzzy Logic based methodology ti rank shop floor dispatching rules, Elsevier,International Journal of Production Economics 76, 99-108 (2002).

[21] N.K.Mahapatra, Decision Process for Multi Objective, Multi Item Prodcution-Invesntory System via Interactive Fuzzy satisfying Technique, Elsevier, Comouters and Mathematics with Applications, 49, 805-821 (2005). 